\title{
ACESSO À JUSTICÇA: INSTRUMENTALIZAÇÃO EM RECONHECIMENTO ÀS ESPECIFICIDADES DAS MICROEMPRESAS E EMPRESAS DE PEQUENO PORTE
}

\author{
Saulo Bichara Mendonça* \\ Márcia Michele Garcia Duarte**
}

SUMÁRIO: Introdução; 1.1 Ponderações acerca da ordem econômica no primado constitucional brasileiro; 2 As microempresas e empresas de pequeno porte no âmbito jurídico; 2.1 Princípio da tutela à pequena e média empresa sob o prisma socioeconômico; 2.2 Tratamento favorecido e diferenciado às microempresas $e$ empresas de pequeno porte; 3 Microempresa e empresa de pequeno porte: elementos processuais já incidentes e os necessários; 3.1 As microempresas e empresas de pequeno porte nos juizados especiais cíveis; 3.2 Súmula 377 do TST; 3.3 Gratuidade de justiça para microempresas e empresas de pequeno porte; 3.4 Mitigação da inversão do ônus da prova nas relações de consumo; 4 Considerações finais; Referências.

RESUMO: Intensas alterações normativas conferiram novas feições à tutela prestada pelo Estado, imprimindo expressivo marco ao Século XX: o acesso à justiça. Seguramente, o Estado Constitucional deve se ocupar de diretrizes e instrumentalização para realização do justo e, nesse cenário, destarte, este estudo se propõe à análise da importância da ótica conferida pela Lei Complementar 123 (BRASIL, 2006), considerando as inovações advindas das alterações registradas, e singulares garantias às pequenas empresas e empresas de pequeno porte. A problemática deste ensaio pauta-se na escassez processual da norma, que deixa de contemplar questões de extrema importância prático-processual. Assegura-se relevância econômica e social das atividades desenvolvidas pela microempresa, a justificar especial tratamento jurídico à luz das reais necessidades para o atingimento da igualdade material e eficiência, singularmente intrínseca nos fundamentos do Estado Democrático de Direito. Para tanto o método analítico auxiliará a verificação da interpretação da lei pela jurisprudência concomitante aos entendimentos doutrinários que conduziram à conclusão de que para ser eficiente, a livre iniciativa depende de instrumentos que permitam atividade empresarial exitosa e próspera, em todas as especificidades, de forma que as microempresas e empresas de

\footnotetext{
Docente Adjunto na Universidade Federal Fluminense (UFF); Pós-doutorando pela Universidade do Estado do Rio de Janeiro (UERJ); Doutor em Direito pela Universidade Veiga de Almeida (UVA), Rio de Janeiro, Brasil. E-mail: saulobmendonca@live.com

${ }^{* *}$ Docente Adjunta da Universidade Federal Fluminense (UFF) e da Universidade do Estado do Rio de Janeiro (UERJ) no Programa de Pós-Graduação em Direito (PPGD); Pós-doutora em Democracia e Direitos Humanos pela Universidade de Coimbra/Portugal; Pós-doutora em Direito Processual, pela Universidade do Estado do Rio de Janeiro (UERJ) e Doutora em Direito pela Universidade EStácio de Sá (UNESA), Rio de Janeiro, Brasil.
} 
pequeno porte necessitam de aparato jurídico especial e pragmático para seu efetivo desenvolvimento e cumprimento de sua função social.

PALAVRAS-CHAVE: Acesso à justiça; Empresas de pequeno porte; Hipossuficiência; Isonomia material; Microempresas; Reconhecimento.

\section{ACCESS TO JUSTICE: INSTRUMENTALITY AS AN ACKNOWLEDGEMENT OF SPECIFICITIES OF MICRO AND SMALL FIRMS}

ABSTRACT: Intensive normative changes have provided different aspects to State's tutelage, with important repercussions in the $20^{\text {th }}$ century, namely, access to justice. The state should take into account the directives and instrumentality to demand what is just. Current analysis deals with the relevance given by Complementary Law 123 (BRASIL, 2006) and takes into account innovations from changes and unique guarantees to small and small-sized firms. Current issue is foregrounded on the process exiguity of the norm which does not deal with issues of great practical and processual importance. Economic and social relevance of activities by micro-firms are assured when special court treatment is justified in the light of the real needs for material and efficient equality, which is greatly intrinsic to the lawful democratic state. The analytic method will verify the interpretation of the law by jurisprudence concomitant to the doctrine that, for efficiency, free initiative depends on tools that permit successful and prosperous entrepreneurship in all specificities. Consequently, micro and small-sized firms require special and programmatic apparatus for their effective development and undertaking of their social function.

KEY WORDS: Access to justice; small-size firms; Hypo-sufficiency; material isonomy; Micro firms; acknowledgement.

\section{ACCESO A LA JUSTICIA: INSTRUMENTALIZACIÓN EN RECONOCIMIENTO A LAS ESPECIFICIDADES DE LAS MICROEMPRESAS Y EMPRESAS DE PEQUEÑO PORTE}

RESUMEN: Intensas alteraciones normativas confirieron novas características a la tutela prestada por el Estado, imprimiendo expresivo marco al Siglo XX: el acceso a la justicia. Seguramente, el Estado Constitucional debe ocuparse de directrices e instrumentalización para realización del justo y, en ese escenario, y por eso, este estudio se propone el análisis de la importancia de la óptica conferida por la Ley Complementar 123 (BRASIL, 2006), considerando las innovaciones advenidas de las alteraciones registradas, y singulares garantías a las pequeñas empresas y empresas de pequeño porte. La problemática de este ensayo se pauta en la escasez procesual 
de la norma, que deja de contemplar cuestiones de extrema importancia prácticoprocesual. Se asegura relevancia económica y social das actividades desarrolladas por la microempresa, a justificar especial tratamiento jurídico a la luz de las reales necesidades para el alcance de la igualdad material y eficiencia, singularmente intrínseca en los fundamentos del Estado Democrático de Derecho. Para tanto el método analítico ayudará la verificación de la interpretación de la ley por la jurisprudencia concomitante a los entendimientos doctrinarios que conducirán a la conclusión de que para ser eficiente, la libre iniciativa depende de instrumentos que permitan actividad empresarial exitosa y próspera, en todas las especificidades, de forma que las microempresas y empresas de tamaño pequeño necesitan de aparato jurídico especial y pragmático para su efectivo desarrollo y cumplimiento de su función social.

PALABRAS-CLAVE: Acceso a la justicia; Empresas de pequeño tamaño; Hiposuficiencia; Igualdad material; Microempresas; Reconocimiento.

\section{INTRODUÇÃO}

Os movimentos registrados no Estado Social, fomentadores de desenvolvimento econômico, industrial e mercantil, são o ponto de partida para este ensaio, pela contribuição salutar para a conversão da atividade comercial em atividade empresária. Verifica-se que, desde então, nova ordem processual e material elevaram microempresa e empresa de pequeno porte ao patamar diferenciado e favorecido, garantido pela Constituição Federal de 1988, seguido da atuação legislativa que, em marcha constante, vem instituindo formas mais isonômicas de atuação dos empresários deste nível de segmento no mercado concorrencial.

Parte-se da investigação acerca do mercado, gravadas nas Constituições do Estado brasileiro até a Constituição Federal de 1988, que anota expressamente elementos atinentes às hoje denominadas microempresas e empresas de pequeno porte. Essa fonte servirá como referencial não apenas para a interpretação das normas defensivas da empresa desenvolvida pelo patamar indicado, mas também para a compreensão das regras processuais impostas a partir das leis que disciplinam os Juizados Especiais, a jurisprudência do TST, a expansão da concessão da justiça gratuita às pessoas jurídicas que gozem de determinado enquadramento jurídico, encerrando-se com a possibilidade de relativização da inversão do ônus da prova 
nas relações consumeristas.

Feita a identificação dos novos contornos jurídicos da microempresa e empresa de pequeno porte, ao final serão apontadas as novas perspectivas no que tange à atividade judicante e a relativização de alguns outros aspectos de direito material, a fim de ampliar a consolidação do reconhecimento da hipossuficiência dessas empresas.

\subsection{PONDERAÇÕES ACERCA DA ORDEM ECONÔMICA NO PRIMADO CONSTITUCIONAL BRASILEIRO}

O sistema jurídico atual ergue-se sobre patamar de novas expectativas, frente à diversidade de situações do mundo da vida, que exigem do Estado respostas rápidas e justas. Os novos paradigmas circunscrevem-se conforme a Régua de Lesbos, permitindo o distanciamento das tensionadas e superadas fórmulas cartesianas a fim de alcançar a igualdade material como elemento caracterizador da verdadeira justiça.

O reconhecimento de que há iguais e desiguais, e que a cada qual deva ser conferido tratamento adequado às diferenças havidas, autoriza o uso do primado da equidade a fim de que, uma vez instituída a matriz jurídica, essa esteja apta a flexibilizar-se em prol do melhor atingimento da justiça social.

Isso se manifesta em diversos seguimentos da sociedade contemporânea, notadamente quando se reconhece a hipossuficiência econômica de determinados grupos. Permitir linguagem própria para cada seara de atuação do sistema jurídico é considerar as peculiaridades dos casos e respeitar suas especificidades reais, de modo que a Justiça seja realizada para além de mera solução de casos de forma vazia, rasa e inefetiva.

É nesse novo cenário que reside a justificativa para que as microempresas e empresas de pequeno porte, ao lado de outros grupos vulneráveis econômicosociais, encontrem guarida no manto protetivo do Estado por meio de matrizes jurídicas diferenciadas, cujo marco teórico que as reconhece como hipossuficientes possa guardar semeadura desde o fenômeno Estado Social, reconhecida fonte dos ideários de incentivos econômicos, de intensas mudanças paradigmáticas e sistematização do direito, com vieses protetivos em caráter coletivo. 
Iniciando a análise das Cartas ${ }^{03}$, parte-se da Constituição da República dos Estados Unidos do Brasil, de 1934, emblemática no marco de transição do Estado Liberal para o Estado Social. Disciplinou a Ordem Econômica e Social, estabelecendo que a primeira devesse ser organizada conforme os princípios da justiça e necessidades da vida nacional, primando por ser "garantida a liberdade econômica" "4; autorizando a intervenção da União nas atividades industriais e atividade econômica mediante lei especial, assegurando-se as indenizações devidas; e respeitando os entes federados municipalizados ou de competência dos poderes locais, que ficavam ressalvados.

Identificou-se fomento à economia popular, pelo estabelecimento de leis em prol da concessão de crédito e nacionalização progressiva dos bancos de depósito, bem como das empresas de seguros. Determinou-se ainda que as sociedades estrangeiras em atividade no país constituíssem-se sociedades brasileiras.

A Carta Constitucional que antecedeu ao escrito de 1934 seguia os ideais do imperador buscando fixar formalmente democracia, sem criar elementos que, de fato, possibilitassem a efetivação desse modelo de sistema de governo. Construída sobre a base de um sistema exploratório que atendia ao poder político derivado de correspondente poder econômico subjacente, desprezando-se os interesses dos hipossuficientes.

Por outro lado, sob perspectiva da relevante influência externa, a Constituição de 1934 seguiu nova ótica. Registre-se o marco político derivado da Constituição de Weimar de 1919, que representou a transição para o Estado Social na Alemanha. Alguns anos depois, o New Deal, instituído por ato governamental com vistas de superar a crise que assolou a economia dos Estados Unidos no final dos anos 1920, por meio do incentivo ao capitalismo e industrialização.

Nesse período histórico, diversas medidas foram tomadas por Getúlio Vargas de modo a ampliar as garantias dos trabalhadores, a exemplo da própria criação de normatização especial obreira, a Consolidação das Leis do Trabalho de 1934; a criação da Justiça do Trabalho, o reconhecimento das atividades sindicais e a conferência de especial disciplina às relações do trabalho campestre, o que, sem dúvidas, repercutiu nas atividades mercantis em todos os seguimentos.

\footnotetext{
${ }^{03}$ Análise das Constituições anteriores realizada pelos autores deste ensaio, partindo dos textos disponibilizados no Portal da Legislação do Governo Federal. Disponível em: http://www4.planalto.gov.br/legislacao/legislacao -historica/constituicoes-anteriores-1\# content. Acesso em: abr. 2015.

${ }^{04}$ Art. 115 da Constituição (Brasil, 1934). Faz-se necessário destacar que a prática de usura foi expressamente proibida (parágrafo único do art. $117 \mathrm{da} C \mathrm{CF} / 1934$ ), recepcionando o Decreto $\mathrm{n}^{0} 22.626$, de 07 de abril de 1933, que disciplinou a questão dos juros contratuais, bem como tipificou como conduta criminosa a prática de usura (art. 13 do Decreto).
} 
A Constituição de 1934 teve breve duração, sendo prematuramente substituída pela Constituição dos Estados Unidos do Brasil de 1937, dotada de sucinta disciplina de ordem econômica e contornos de retrocesso ao autoritarismo, o que se evidencia em trechos como:

A intervenção no domínio econômico poderá ser mediata e imediata, revestindo a forma do controle, do estímulo ou da gestão direta. Justificava a intervenção como de "maneira a evitar ou resolver os seus conflitos e introduzir no jogo das competições individuais o pensamento dos interesses da Nação, representados pelo Estado.

A despeito dessa postura, a Carta também promovia o fomento à economia popular com garantias especiais; os crimes contra a economia popular eram tidos como crimes graves contra o Estado, justificando a aplicação de reprimenda severa.

A Constituição dos Estados Unidos do Brasil, de 1946, traçou maior ocupação com a questão coletiva, invocando os princípios da justiça social de modo a tentar conciliar a liberdade de iniciativa com a valorização do trabalho humano, sendo essas as matrizes da ordem econômica. A intervenção no domínio econômico tinha por base o interesse público, respeitando os limites dos direitos fundamentais assegurados na Carta Maior, em evidente evolução referente ao texto anterior que justificava o domínio econômico diante do interesse do Estado.

A repressão ao abuso do poder econômico perpetrado, inclusive, pelo agrupamento de empresas individuais ou sociais com o objetivo de aumentar arbitrariamente os lucros e eliminar a concorrência, confirmou a relevância da Carta de 1946 para o interesse coletivo e à promoção da atividade econômica, sendo salutar o incentivo à ascensão das atividades de mercado com menor expressão econômica.

A Carta de 1946 deu novo impulso ao reestabelecimento dos ideais do Welfare State, o que também refletiu na ordem econômica, tendo como uma das cláusulas sociais a repressão ao abuso do poder econômico e valorização dos direitos trabalhistas, com respeito ao trabalho humano, fortemente influenciado pela valorização da pessoa humana, notadamente quando a nação ainda cicatrizava os horrores da Segunda Guerra.

O golpe militar abreviou a Carta de 1946, seguindo-se a Constituição de 1967, da Emenda de 1969 e dos Atos Institucionais, como forma de paralização do sistema de garantias e crescimento econômicos, mitigando primados que justificaram a Carta anterior.

A Carta de 1967 disciplinou a busca formal pela realização da justiça social, caracterizada pela previsão expressa dos princípios da liberdade de iniciativa, 
desenvolvimento econômico, repressão ao abuso do poder econômico e pelo princípio da harmonia e solidariedade entre os fatores de produção. Quanto à intervenção no domínio econômico, assegurou a possibilidade de monopólio de indústria ou atividade mediante lei da União a fim de atender à segurança nacional ou organização de setor que não pudesse ser desenvolvido com liberdade de iniciativa e eficiência no regime de competição. Sem prejuízo disso, limitou a produção de bens supérfluos por empresa, proibindo à pessoa física a participação em mais de uma empresa ou de uma empresa em outra, comando esse revogado pelo Ato Institucional no 9 (BRASIL, 1969).

A Emenda Constitucional $n^{\circ} 01$ (BRASIL, 1969) agregou ao rol dos princípios o do desenvolvimento nacional, ao lado da justiça social, substituiu a expressão fatores de produção por categorias sociais de produção e incluiu a expansão das oportunidades de emprego produtivo.

A intervenção no domínio econômico e o monopólio de determinada indústria era autorizada mediante lei federal justificada por força de supremacia da segurança nacional ou para assegurar o desenvolvimento com eficácia no regime de competição e de liberdade de iniciativa.

A Carta Cidadã (BRASIL, 1988), a primeira depois do período militar, revelou a valorização do trabalho humano e a livre iniciativa como o introito da ordem econômica e financeira, e apontou os princípios gerais da atividade econômica.

Destacam-se para este estudo o princípio da soberania nacional, pautado no interesse público, seguido do princípio da propriedade privada; a livre concorrência seguindo-se da defesa do consumidor e do meio ambiente; a redução das desigualdades regionais e sociais seguida da expressa disposição para tratamento favorecido a ser dispensado às empresas de pequeno porte, texto esse que a partir da EC ñ 06 (BRASIL, 1995), teve sua redação incluída da expressão "constituídas sob as leis brasileiras e que tenham sua sede e administração no País", consoante se verifica no inciso IX, do art. 170 (BRASIL, 1988).

A atividade econômica passou a ser livremente exercida, admitindo-se que se realize sem a autorização de órgãos públicos, salvo exceções legais; a exploração direta de atividade econômica pelo Estado passou a ser permitida somente quando necessária à segurança nacional ou quando houver relevante interesse coletivo; e o Estado deve instituir leis para a repressão ao abuso do poder econômico.

A leitura do breve histórico das Constituições permitiu-nos observar a interferência do Estado na economia no significativo período de transição que se deu no Século XX, embora o tratamento singular em favor de empresas de menor 
poderio econômico só tenha sido expressado na Carta Constitucional (BRASIL, 1988).

Isso denota quão negligenciado foi esse seguimento presente na realidade brasileira, não obstante a notória vulnerabilidade e hipossuficiência das atividades mercantis familiar e de pequenos grupos empresariais, que se realizam desde tempos longínquos.

Devemos reconhecer, entretanto, o expressivo movimento jurídico - ainda que tardio - em favor da concessão de tratamento justificadamente diferenciado às empresas hipossuficientes, estampado na Lei Maior, na disciplina infraconstitucional e nas decisões judiciais.

Isso nos impulsiona à postura otimista no que tange às possíveis modificações vindouras, na expectativa de que impulsionem o funcionamento das atividades e saúde financeira das microempresas e empresas de pequeno porte e, mediante isso, caminhe-se, de fato, para realização da efetiva justiça.

\section{AS MICROEMPRESAS E EMPRESAS DE PEQUENO PORTE NO ÂMBITO JURÍDICO}

A compreensão do tratamento favorecido e diferenciado destinado às microempresas e empresas de pequeno porte, assim definidas pelo artigo $3^{\circ}$ da Lei Complementar $n^{0} 123$ (BRASIL, 2006) ${ }^{05}$, em atenção aos termos dos mencionados artigos 170, inciso IX e 179 da Constituição Federal (BRASIL, 1988), exige considerar a empresa enquanto atividade, tal como assinalada por Alberto Asquini ${ }^{06}$, em sua teoria poliédrica, inobstante o próprio autor não aceitar a poliedria da empresa ${ }^{07}$.

\footnotetext{
${ }^{05}$ Art. $3^{\circ}$ Para os efeitos desta Lei Complementar, consideram-se microempresas ou empresas de pequeno porte, a sociedade empresária, a sociedade simples, a empresa individual de responsabilidade limitada e o empresário a que se refere o art. 966 da Lei no 10.406 , de 10 de janeiro de 2002 (Código Civil), devidamente registrados no Registro de Empresas Mercantis ou no Registro Civil de Pessoas Jurídicas, conforme o caso, desde que:

I - no caso da microempresa, aufira, em cada ano-calendário, receita bruta igual ou inferior a $\mathrm{R} \$ 360.000,00$ (trezentos e sessenta mil reais); e

II - no caso da empresa de pequeno porte, aufira, em cada ano-calendário, receita bruta superior a $\mathrm{R} \$ 360.000,00$ (trezentos e sessenta mil reais) e igual ou inferior a $\mathrm{R} \$ 3.600 .000,00$ (três milhões e seiscentos mil reais).

${ }^{06}$ ASQUINI, Alberto. Profili dell' 'impresa. Rivista di diritto commerciale, Milano, v. XLI, parte I, p. 01-20, 1943.

07 "O próprio autor, que, como já dito alhures, se limitou a narrar o fato, critica a identificação da empresa com o empresário ou com o estabelecimento. No mesmo sentido é que aludiu aos tais "perfis", defendeu um tratamento mais apurado da matéria, reconduzindo a empresa a limites mais estreitos do que os usualmente aceitos. Também para Asquini, a empresa não se confunde com empresário nem tampouco com o estabelecimento. O jurista aponta, repita-se, a incorreção do emprego do vocábulo em tais acepções". DUARTE, Ronnie Preuss. Teoria da Empresa: a luz do novo Código Civil brasileiro. São Paulo: Método, 2004. p. 89.
} 
Pode-se encontrar o prospecto desta atividade econômica destinada a proporcionar lucro ao empreendedor na Idade Média $^{08}$, onde já se verificava nas oficinas de artesãos, sua importância como organização socioeconômica; promissora como objeto de estudos por juristas e economistas, tanto que sua definição jurídica decorre do conceito econômico, sendo desnecessária a distinção entre estas, como assinalam alguns autores.

Porém, esta atividade econômica nuclear, desenvolvida por artesãos, em um contexto familiar, se vê superada tecnologicamente, em decorrência da natural ambição humana que impulsionou os avanços sociais focados na eficiência em prol do sedentarismo coletivo, que culminaram na Revolução Industrial no século XVIII.

No caso do Brasil, a despeito da legislação empresarial derivar da Teoria da Empresa Italiana, o legislador pátrio reconheceu a relevância da empresa familiar, identificando a família como agente econômico pré-expansão do capitalismo industrial, convertendo-a por regulação em microempresas e empresas de pequeno porte, concedendo-as tratamento favorecido e diferenciado, a despeito do "triunfo do capitalismo industrial"09.

As empresas familiares não proporcionavam meios para os empreendedores especialistas, e tenderiam à marginalização, não fosse a legislação pátria enquadrar o tema em um contexto regulatório específico, mesmo antes da Constituição Federal (BRASIL, 1988), respeitando a alternativa de prosperidade e crescimento econômico a partir do núcleo social familiar.

Desta forma, a microempresa e a empresa de pequeno porte analisadas pelo prisma da função social da empresa alija a figura do então magnata, que se assemelhava à figura do senhor feudal, a qual era, naquele momento, "uma figura incômoda, sugerindo as ideias de exploração dos empregados e de práticas de corrupção, além de uma considerável gama de procedimentos condenáveis"10, substituindo-o pela figura do empresário (administrador, executivo ou business man).

Vê-se como imprescindível o estudo do tema sob o prisma da função social da empresa ${ }^{11}$, pois dentre todos os portes, as microempresas e a empresa de pequeno

\footnotetext{
${ }^{08}$ ALMEIDA, Amador Paes de (coord.). Comentários ao Estatuto da Microempresa e Empresa de Pequeno Porte. São Paulo: Saraiva, 2009, p. 10.

${ }^{09}$ GONÇALVES, Sérgio de Castro. Patrimônio, família e empresa. Um estudo sobre a transformação no mundo da economia. São Paulo: Negócio Editora, 2000. p. 26.

${ }^{10}$ GONÇALVES, Sérgio de Castro. Patrimônio, família e empresa. Um estudo sobre a transformação no mundo da economia. São Paulo: Negócio Editora, 2000. p. 29.

11 "A função da empresa vai além da promoção de retorno remunerado do investimento realizado pelo empresário; sua regulamentação, que é abrangida por setores diversos do direito (empresarial, trabalho, previdenciário, consumidor, tributário, ambiental, contratos, penal e processo) passa a exigir um resultado que se aproveite por terceiros que não os investidores". MENDONÇA, Saulo Bichara. Função social da empresa. Análise pragmática. Revista de Estudos Jurídicos UNESP. Disponível em: < http://seer.franca.unesp.br/index. php/estudosjuridicosunesp/article/view/479>, p. 72.
} 
porte são as que melhor permitem a verificação da funcionalização, uma vez que, não apenas propiciam a persecução do lucro, como proporcionam afinidade entre os propósitos econômicos e sociais, gerando quantidade de empregos em regiões menos atrativas economicamente corroborando com a proposta de uma política social que culmine na consagração da justiça social.

\subsection{PRINCÍPIO DA TUTELA À PEQUENA E MÉDIA EMPRESA SOB O PRISMA SOCIOECONÔMICO}

Há registros de que ainda na década de 1970, o então Ministro Hélio Beltrão $0^{12}$, no comando do Ministério da Desburocratização, defendia a tutela às microempresas e empresas de pequeno porte, em razão da forma como estas interagiam no contexto econômico.

Este é um país onde predomina o pequeno; um país onde $90 \%$ da população se constitui de pessoas de baixo nível de renda, em luta contra toda sorte de dificuldades, onde $95 \%$ dos municípios não têm recursos sequer para satisfazer às necessidades essenciais da população; onde $80 \%$ das empresas têm menos de cinco empregados e 95\%, menos de cem empregados, funcionando geralmente em condições de insuficiente capitalização e excessivo endividamento ${ }^{13}$.

O Estatuto da Microempresa registrou primeira edição com a Lei ${ }^{\circ} 7.256$ (BRASIL, 1984), sendo revogado pela Lei $n^{\circ} 8.864$ (BRASIL, 1994), seguida pela Lei $\mathrm{n}^{\circ} 9.317$ (BRASIL, 1996) e pela Lei ${ }^{\circ} 9.841$ (BRASIL, 1999) que precede a atual Lei Complementar $n^{\circ} 123$ (BRASIL, 2006), tendo sua última alteração sido realizada pela Lei Complementar $\mathrm{n}^{\circ} 147$ (BRASIL, 2014), entretanto, "pequenas empresas ainda sofrem com a inexistência de um tratamento mais adequado" 14 .

A preocupação do então Ministro Hélio Beltrão ainda se justifica como atual a partir dos dados do Instituto Brasileiro de Geografia e Estatística, segundo

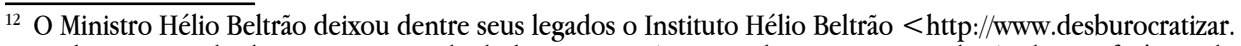
org.br/ $>$, oriundo do seu programa de desburocratização que tinha por meta a redução da interferência do Governo na atividade particular do cidadão e do empresário, visando solucionar de forma eficiente, mediante a descentralização das decisões, a simplificação do trabalho administrativo e a eliminação de formalidades desnecessárias e exigências cujo custo econômico ou social seja superior ao risco do empreendimento nos casos em que essa interferência seja imprescindível.

${ }^{13}$ BELTRÃO, Hélio. A Pequena e média empresa como fator de estabilidade política, econômica e social. Senai: Brasília, 1983.

${ }^{14}$ OLIVEIRA, Otávio J. Pequena empresa no Brasil: um estudo de suas características e perspectivas. Revista Integração, São Paulo, ano XII, n. 44, p. 8, jan. fev. mar. 2006. Disponível em: <ftp://ftp.usjt.br/pub/revint/5_44. pdf $>$. Acesso em: 01 mai. 2013. 
o qual, "em outubro de 2003, existiam no Brasil 10.525.954 pequenas empresas não agrícolas, das quais 98\%, ou seja, 10.335 .962 pertenciam ao setor informal e ocupavam 13.860 .868 pessoas" ${ }^{15}$, fato que, dentre outros registros estatísticos, motivou a criação da a Secretaria da Micro e Pequena Empresa, vinculada à Presidência da República, órgão com status de Ministério, pela Lei n ${ }^{0} 12.792$ (BRASIL, 2013).

Os debates no legislativo no sentido de persistir na regulação de meios que permitam o fomento econômico permanecem ativos. Isso se percebe a partir da então Medida Provisória 651 convertida na Lei $n^{\circ} 13.043$ (BRASIL, 2014) que isenta o imposto de renda sobre alienação de ações de pequenas e médias empresas em bolsa de valores viabilizando o fomento ao desenvolvimento do mercado e ampliação da competitividade da produção nacional.

Tais fatos, apesar da relevância que ostentam, como se ressalta, não permitiram conhecer pelo Código Civil (BRASIL, 2002) mais do que o constante no seu artigo 970, o que não vai além do determinado pela Constituição Federal (BRASIL, 1988); ao menos, a regra geral não afrontou a especial, pois não seria aceitável "diversidade de critérios entre o Código Civil e os estatutos que cuidam das microempresas e empresas de pequeno porte" ${ }^{\text {"16 }}$, nos termos da Lei de Introdução às Normas do Direito Brasileiro.

\subsection{TRATAMENTO FAVORECIDO E DIFERENCIADO ÀS MICROEMPRESAS E EMPRESAS DE PEQUENO PORTE}

No que tange ao processo de abertura, registro, alteração e baixa do microempreendedor individual, nos termos do artigo 18-A da Lei Complementar $n^{0}$ 123 (BRASIL, 2006) há previsão de trâmite especial e simplificado, preferencialmente eletrônico, para seu registro; tal como se perceba disciplinado pelo Comitê para Gestão da Rede Nacional para a Simplificação do Registro e da Legalização de Empresas e Negócios; podendo inclusive ser dispensados o uso da firma, com a respectiva assinatura autógrafa, o capital, requerimentos, demais assinaturas, informações relativas à nacionalidade, estado civil e regime de bens, bem como remessa de documentos, na forma estabelecida pelo referido Comitê ${ }^{17}$.

\footnotetext{
${ }^{15}$ IBGE. Sala de Imprensa. Brasil tem mais de 10 milhões de empresas na informalidade. Disponível em: $<$ http://saladeimprensa.ibge.gov.br $/$ noticias? view $=$ noticia\&id $=1 \&$ busca $=1 \&$ idnoticia $=366>$. Acesso em: 10 abr. 2015.

${ }^{16}$ RIZZARDO, Arnaldo. Direito de Empresa. $5^{\mathrm{a}}$ ed. revista, atualizada e ampliada. Rio de Janeiro: Forense, 2014, p. 59.

${ }^{17}$ A facilitação no trâmite burocrático de registro das microempresas e empresas de pequeno porte derivam da Lei $\mathrm{n}^{\circ} 12.470$ (BRASIL, 2011) que acrescentou os parágrafos $4^{\circ}$ e $5^{\circ}$ ao artigo 968 do Código Civil Brasileiro.
} 
O Estatuto da Microempresa apresenta também tratamento diferenciado, na perspectiva de Wilges Bruscato, no que tange à apuração e recolhimento de impostos, contribuições e obrigações acessórias mediante regime único de arrecadação. Igualmente, observa dispensa de algumas obrigações trabalhistas, de cunho administrativo e previdenciárias, e sublinha especial diretriz conferida que permite: "facilitação ao acesso ao crédito, tecnologia, associativismo, regras de inclusão e mercado, inclusive quanto à preferência nas aquisições de bens e serviços pelos poderes públicos"18.

Registram-se ainda benefícios na participação das microempresas e empresas de pequeno porte nos certames licitatórios; a dispensa no cumprimento de determinadas formalidades administrativas atinentes às obrigações laborais, para com os colaboradores da empresa contratados pelo regime celetista; a previsão de manutenção de linhas de crédito específicas, ofertadas por instituições bancárias públicas e a ausência de taxas para protestos de títulos quando o devedor for microempresa ou empresa de pequeno porte.

No que tange à recuperação judicial de empresas, a Lei no 11.101 (BRASIL, 2005), igualmente alterada pela Lei Complementar $n^{0} 147$ (BRASIL, 2014), aborda 0 tema, nos artigos 70 a 72 e 48, inciso III, sem, contudo, demonstrar distanciamento da extinta concordata, alijando a possibilidade do devedor negociar com seus credores em assembleia e determinado a incidência de juros nas prestações a que fica obrigado o devedor, limitadas ao total de trinta e seis; apesar da recente inovação ainda não se permite defender a regulação de uma real possibilidade de novação em respeito à função social dos contratos.

No âmbito processual, o artigo $8^{\circ}, \S 1^{\circ}$, inciso II da Lei $\mathrm{n}^{\circ} 9.099$ (BRASIL, $1995)$ autoriza a propositura de ações por microempresas e empresas de pequeno porte, nos termos da Lei Complementar $n^{0} 123$ (BRASIL, 2006).

Contudo, apesar do pretenso favorecimento processual, atinente à propositura da ação pelo rito do Juizado Especial, o desenrolar do litígio pode não legitimar positividade na verificação da determinação constitucional, em especial no que tange à inversão do ônus da prova.

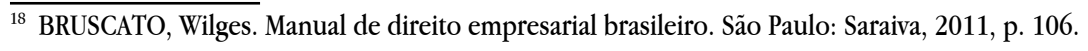




\section{MICROEMPRESA E EMPRESA DE PEQUENO PORTE: ELEMENTOS PROCESSUAIS JÁ INCIDENTES E OS NECESSÁRIOS}

Para ser considerado efetivo e eficaz, o acesso à justiça deve ser justo e atender à completude da atuação do Estado na tarefa de proteger interesses e conferir justiça em sentido amplo, isso para além de disposições normativas e decisões judiciais. Deve atender aos preceitos mínimos de pacificação de conflitos e à promoção de igualdade material nos âmbitos judicial e extrajudicial, bem como estabelecer a justa relação jurídica de direito material.

Considerando os parâmetros de acesso à justiça, notadamente pela via da judicialização de causas, e o estudo em enfoque que resguarda especial atenção às microempresas e empresas de pequeno porte, merece especial relevo o microssistema dos Juizados Especiais (JEs), na medida em que esse se mostra inegável instrumento de ampliação do acesso ao Judiciário.

A legislação originária dos JEs, datada de 1995, recebeu alterações de modo a contemplar como figura jurídica demandante também as microempresas e empresas de pequeno porte, revelando preciosa alteração que confere a esse seguimento empresarial os benefícios do procedimento diferenciado e dos princípios específicos que tangenciam os Juizados. Inegavelmente, isso representa abertura concreta de acesso ao Judiciário e, formalmente, o acesso à justiça.

Outras questões como a gratuidade de justiça conferida à pessoa jurídica e os procedimentos para a representação das microempresas e empresas de pequeno porte em audiências judiciais também estão sendo circunscritas na agenda jurídica contemporânea, conforme será analisado nas linhas que seguem.

\subsection{AS MICROEMPRESAS E EMPRESAS DE PEQUENO PORTE NOS JUIZADOS ESPECIAIS CÍVEIS}

Os Juizados Especiais representam nova era do acesso à justiça no Brasil. A criação de um seguimento do Judiciário destinado a atender causas de menor monta, entretanto, não representa inovação ${ }^{19}$, mas, sublinhe-se, a via dos JEs da atualidade

\footnotetext{
${ }^{19}$ Os juízos para julgamentos de causas de menor monta não são inovação da jurisdição moderna. Desde os tempos dos visigodos dividiam-se as causas em menor ou maior monta para julgamentos de forma diferenciada. Sobre esse tema, sugere-se a leitura de: Os Juizados Especiais Cíveis e o e-Process: O Exame das Garantias Processuais na Esfera Virtual, disponível em: < http://www.redp.com.br/arquivos/redp_3a_edicao.pdf $>$. Acesso em: out. 2014.
} 
é um dos símbolos de mudança postural do Estado no aspecto tutela jurídica diferenciada aos menos favorecidos, notadamente do ponto de vista econômico.

Instituído pelo texto da Constituinte de 1988, foram criadas leis nacionais para disciplinar os Juizados Especiais Cíveis e Criminais, os Juizados Especiais Federais e os Juizados Especiais Estaduais da Fazenda Pública.

Inseridos em pontos e contrapontos da polêmica jurídica, os Juizados Especiais foram duramente rechaçados por alguns que os consideram banalização da justiça e, o fenômeno da judicialização, como um modismo. Por outros, entretanto, os JEs são veementemente defendidos sob a exegese de democratização da justiça por viabilizar pleno exercício do direito de ação, inclusive, das demandas reprimidas pelos obstáculos econômicos tão evidentes no espaço social.

Paralelamente a isso, o Código de Defesa do Consumidor igualmente fomentou o ajuizamento de ações, tendo como solo a arena dos JEs, perfeitamente adequável ao exercício dos direitos consagrados pela norma consumerista.

Registre-se que, originalmente, as pessoas jurídicas figuravam apenas como rés nos JEs, agregado o peso da responsabilidade civil objetiva e inversão do ônus da prova que se impunham em desfavor daquelas.

Somente no ano de 2009, o texto legislativo original que restringia o ajuizamento de causas nos JEs apenas por pessoas físicas capazes, foi alterado pela Lei $\mathrm{n}^{\mathrm{O}} 12.126$ (BRASIL, 2009), que insertou as microempresas no rol de legitimados ativos para causas de competência dos JEs, estendendo-se tal permissivo àquelas pessoas jurídicas qualificadas como Organização Civil de Interesse Público e as sociedades de crédito ao microempreendedor.

Atualmente, o inciso II, do $\$ 1^{\circ}$, do art. $8^{\circ}$ da Lei n ${ }^{\circ} 9.099$ (BRASIL, 1995), com redação dada pela Lei Complementar $n^{\circ} 147$ (BRASIL, 2014), garante igual condição às pessoas enquadradas como microempreendedores individuais, microempresas e empresas de pequeno porte, assim qualificadas pela Lei Complementar $n^{0} 123$ (BRASIL, 2006).

A dita inovação, em verdade, equiparou o que já vinha ocorrendo perante os Juizados Especiais Federais. A Lei n ${ }^{0} 10.259$ (BRASIL, 2001) já previa em seu art. $6^{\circ}$ que as microempresas e empresas de pequeno porte, então definidas pela Lei $\mathrm{n}^{\circ} 9.317$ (BRASIL, 1996), revogada pela Lei Complementar $\mathrm{n}^{\mathrm{o}} 123$ (BRASIL, 2006), poderiam ser autoras nas causas de competência dos JEFs.

Os Juizados Especiais Estaduais da Fazenda Pública, disciplinados pela Lei $\mathrm{n}^{\mathrm{O}} 12.153$ (BRASIL, 2009), seguindo a tendência de tratamento diferenciado 
dispensado às empresas de pequeno porte e microempresas, igualmente autorizou expressamente que as modalidades de pessoas jurídicas pudessem ser parte no microssistema; e foi por meio do Fórum Nacional dos Juizados Especiais ${ }^{20}$ que se instituíram verbetes com tratativas específicas para as microempresas e empresas de pequeno porte.

Assinalando-se os benefícios expandidos às pessoas jurídicas em JEs, temse que, à exceção da regra processual que impõe à parte ser representada em juízo por advogado regularmente constituído, confere-se então o que ousamos denominar de pseudocapacidade postulatória às partes ME EPP, que também podem falar em juízo sem causídico.

O expresso nos $\S 1^{\circ}$ e caput, do art. $9^{\circ}$ da Lei ${ }^{0} 9.099$ (BRASIL, 1995), assegura à parte sem advogado que se depara com ex adverso assistido de causídico, o direito ao pleito pela assistência judiciária prestada por órgão que funcionar junto ao Juizado. O Enunciado 48 faz com que essa regra se estenda de modo a também beneficiar parte autora pessoa jurídica nas modalidades microempresas e empresas de pequeno porte.

Quanto à comprovação da condição de microempresa e empresa de pequeno porte junto aos Juizados Especiais, nos termos do Enunciado 135, isso deve ser feito por meio do indicativo de qualificação tributária atualizada e documento fiscal referente ao negócio jurídico que gerou a demanda. Na militância, observa-se que os juízos estaduais fluminenses exigem o contrato social e o mais recente recibo de declaração de imposto de renda da PJ, para averiguar o enquadramento jurídico da parte autora.

O terceiro enunciado que trata das questões atinentes ao objeto deste estudo refere-se à representação, inclusive em audiência, que deve ser feita pelo empresário individual ou pelo sócio dirigente. Acredita-se que tal verbete deverá sofrer modificações em breve, haja vista a tendência de uniformização dos julgados que tanto se almeja na prestação jurisdicional, o que se evidencia com a nova tratativa conferida pelo CPC (BRASIL, 2015) às decisões judiciais.

Sugerimos que haverá essa substituição do texto do Enunciado 141 do FONAJE na medida em que, na Justiça do Trabalho, reconheceu-se a falta de cabimento prático do enunciado original da Súmula 377 do TST, similar ao estudado acima e, com isso, tem-se por relativizada a exigência de que o preposto integre os

${ }^{20}$ Foram analisados os Enunciados atualizados até o XXXVIII FONAJE (Belo Horizonte - MG). Disponível em: $<$ http://www.fonaje.org.br/site/enunciados/> . Acesso em: jan. 2016. 
quadros de empregados ou societários da pessoa jurídica em juízo, desde que as mesmas se qualifiquem como microempresas e empresas de pequeno porte.

Questões processuais relevantes como as até aqui descritas, salientam como o acesso à justiça pleno merece constante atualização e revisão de preceitos. As pessoas jurídicas notoriamente vulneráveis necessitam de tratamento distinto, enquadramento e disciplina próprias como forma de evitar que sejam asfixiadas pelas amarras da burocracia, tributação desproporcional e sobrecarga de responsabilidades que possam macular e comprometer o vigor da atividade empresária.

\subsection{SÚMULA 377 DO TST}

A Súmula 377 do TST derivou-se da Orientação Jurisprudencial $n^{\circ} 99$ da SBDI- ${ }^{21}$. A redação originária exigia que o preposto que representasse a pessoa jurídica em juízo deveria ser, necessariamente, empregado da empresa ou integrante do seu quadro societário, excetuando-se apenas a hipótese de reclamação de empregado doméstico.

A nova redação conferida ao verbete sumular, agora não só contemplando expressamente o texto da CLT, como também o art. 54 da Lei Complementar n ${ }^{0} 123$ (BRASIL, 2006), disciplina ser facultado ao empregador de microempresa e empresa de pequeno porte fazer-se substituir ou representar perante Justiça Obreira por terceiros não empregados ou sem vínculo societário, bastando que o representante conheça os fatos. Com isso, no que tange à representação em juízo, a regra equiparou aos empregadores domésticos, os micro e pequenos empresários.

Tal adaptação à nova sistemática de percepção das reais necessidades das microempresas e empresas de pequeno porte é salutar por reconhecer-lhes sua vulnerabilidade patente, já que muitas vezes a atividade empresária realiza-se por meio da força laboral dos membros de uma família ou de pequenos grupos de empreendedores sem força expressiva no contingente econômico, situações em que a ausência de um dos trabalhadores na rotina, ainda que momentânea, possa gerar impactos na cadeia produtiva daquela atividade mercantil.

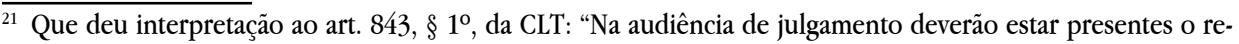
clamante e o reclamado, independentemente do comparecimento de seus representantes salvo, nos casos de Reclamatórias Plúrimas ou Ações de Cumprimento, quando os empregados poderão fazer-se representar pelo Sindicato de sua categoria. $\S 1^{\circ}$ É facultado ao empregador fazer-se substituir pelo gerente, ou qualquer outro preposto que tenha conhecimento do fato, e cujas declarações obrigarão o proponente". 


\subsection{GRATUIDADE DE JUSTIÇA PARA MICROEMPRESAS E EMPRESAS DE PEQUENO PORTE}

A conferência dos benefícios da justiça gratuita para as pessoas jurídicas não representa qualquer inovação ou controvérsia, mas justificamos que seja anotada uma vez que esta pesquisa que tem o propósito de analisar as modificações do contexto jurídico que foram implementadas de modo a ampliar o acesso à justiça para as Empresas de Pequeno Porte e Microempresas.

A Lei $n^{0} 1.060$ (BRASIL, 1950) disciplina a gratuidade de justiça no sistema pátrio, contemplando expressamente apenas os interesses das pessoas físicas. Até o encerramento deste estudo não havia qualquer alteração normativa implementada ou mesmo proposições legislativas que pudessem conceder o benefício também às pessoas jurídicas, igualmente hipossuficientes econômicas.

A atividade judicante contemporânea, no entanto, pousa sobre uma nova forma de executar o monopólio da jurisdição: o ativismo judicial, que, em suma, justifica que o Poder Judiciário não só dite acerca daquilo que a norma omitiu, como também insurja de modo a dar azo à aplicação do direito contrariando textos positivados, desde que as decisões sejam pautadas em princípios reconhecidos.

No exercício do ativismo judicial, o Superior Tribunal de Justiça determinou que o alcance da norma contemplasse as pessoas jurídicas que também se encontrem em situação de necessidade. Para a Corte, atividades mercantis que não persigam fins lucrativos, que se dediquem às atividades beneficentes, filantrópicas e similares, bem como as microempresas, notadamente aquelas que decorram de atividades familiares ou artesanais, são presumidamente hipossuficientes econômicas, e podem pleitear a concessão da benesse da justiça integralmente gratuita.

Isso permite que a pessoa jurídica reconhecidamente hipossuficiente possa contar com a isenção de custos e custas processuais, bem como estará isenta do pagamento de honorários de sucumbência e periciais, poderá obter acesso gratuito aos documentos notariais e registrais, além de poder contar com a assistência integral e gratuita de representante processual.

Salutar posicionamento reforça o princípio constitucional da inafastabilidade do Poder Judiciário e interpretação teleológica reservada à aplicação do direito, casuisticamente. Diante da amplitude que essa inovação alcança, podemos intitulá-la como um dos mais preciosos dentre os avanços alcançados na jornada 
de reconhecimento de necessidades especiais das pessoas jurídicas em situação de vulnerabilidade econômica.

\subsection{MITIGAÇÃO DA INVERSÃO DO ÔNUS DA PROVA NAS RELAÇÕES DE CONSUMO}

A Lei ${ }^{0} 8.078$ (BRASIL, 1990) introduziu no direito pátrio nova ordem para as relações consumeristas. Tido como microssistema, estabeleceu critérios principiológicos, de direito material civil e penal, processual e também contempla o âmbito administrativo.

Para este estudo ${ }^{22}$, destaca-se um dos grandes impactos gerados pelo Código de Defesa do Consumidor: a possibilidade de relativização da teoria da carga dinâmica da prova. Como regra do processo civil, tem-se que o ônus da prova compete ao autor quanto aos fatos constitutivos do seu direito; e ao réu, aquilo de afirma como modificativo, extintivo ou impeditivo do direito do autor.

Contrariando essa regra, o sistema das relações de consumo instituiu a possibilidade de inversão do ônus da prova em favor do autor, o que ganhou intensa relevância jurídico-social.

Embora comumente entendida como uma máxima regra absoluta, a inversão do ônus probandi, em verdade, exige que alguns critérios sejam observados pelo julgador que poderá ou não a deferir. Cuida-se da inversão ope judicis, que assegura àquele que está no exercício da judicatura apreciar a situação concreta, segundo as regras ordinárias de experiência, de modo a aferir a presença da verossimilhança do alegado ou hipossuficiência do consumidor, e então deferir o benefício da inversão do ônus da prova.

Para este estudo, aventa-se que, em algumas situações concretas, a vulnerabilidade pode se apresentar de forma inversa, a que denominamos de bipossuficiência invertida.

Sugere-se partir da hipótese de o demandado da relação consumerista (fornecedor de produtos ou serviços) ser economicamente mais frágil do que o consumidor demandante. Impor ao réu, indistintamente, o ônus processual

\footnotetext{
${ }^{22}$ O tema está sendo objeto de estudo no Grupo de Pesquisa Direito das Empresas e Outros Direitos, em curso na Universidade Federal Fluminense (UFF), Departamento de Direito de Macaé, tendo como aluna pesquisadora engajada Mayra Lima Custódio, desde o semestre letivo 2014.2 e no semestre letivo de 2016.2 a referida aluna apresentou trabalho de conclusão de curso intitulado "O tratamento diferenciado concedido às micro e pequenas empresas na realização de aquisições públicas", inspirado nas pesquisas iniciais que deram ensejo ao presente artigo.
} 
partindo da análise formal dos requisitos que atendam ao interesse do autor, sem a ponderação necessária e avaliação casuística das necessidades do réu, induz à decisão judicial nociva que fere preceitos das garantias processuais e à ordem jurídica.

Ora, pelo exposto ao longo desta narrativa, é possível afirmarse que o reconhecimento da vulnerabilidade econômica de determinados grupos empresariais (a exemplo daqueles citados pelo STJ para receberem a benesse da justiça gratuita), é elemento imprescindível à realização da justiça.

Decerto, o consumidor goza de presunção geral de vulnerabilidade, e o que destacamos, é a cautela com que a temática merece ser tratada.

Nessa senda, concedemos especial relevo à necessidade de se compreender, como institutos distintos, a vulnerabilidade e inversão do ônus da prova.

Embora a segunda decorra da primeira, a incidência da vulnerabilidade (da ordem material, ampla e presumida) não automatiza a inversão do ônus probatório (da ordem processual, restrita e ope juris).

Sublinhamos que as teorias que revestem a responsabilidade civil objetiva (do risco integral; da atividade; do empreendimento) não podem ser justificativas mecanizadas e sinônimo de inversão do ônus. A responsabilidade civil objetiva do fornecedor (independentemente de culpa) é bastante para que ao consumidor incumba apenas a indicação do nexo causal e do dano suportado. Portanto, a instrução probatória será menos complexa do que nos casos em que a comprovação da culpa seja elemento imprescindível à reparação civil (responsabilidade civil subjetiva).

O consumidor vulnerável está singularmente coberto pelo manto protetor normativo e jurisprudencial que, naturalmente, conduzirá ao êxito processual, quando a razão lhe assistir.

Há de se observar ainda que, concretamente, a inversão do ônus da prova encontrará campo restrito, uma vez que as excludentes da responsabilidade civil do fornecedor já são de atribuição comprobatória do fornecedor. Em complementação, a inversão do ônus da prova não tem correlação direta com o resultado da demanda, ou seja, mesmo sendo deferida a inversão pleiteada, o resultado final pode ser de improcedência do pedido.

Dito isso, ressaltamos que essa análise tem o propósito de distinguir o joio do trigo. Entendemos que, na instrução probatória, o juiz deve adotar conduta de realização da justiça, com igualdade material, ainda que isso revele indeferimento do 
pleito autoral de inversão em prol de beneficiar o demandado, quando, analisando a situação concreta, o magistrado identificar que o réu não suportará a produção da prova sem prejuízo de sua atividade. Isso representa acesso à justiça para o demandado, no exercício constitucional da ampla defesa e contraditório, e direito ao provimento justo.

Portanto, a fragilidade econômica da pessoa jurídica aqui destacada não tem o propósito de inibir o dever de indenizar ou reparar o dano que foi gerado em prejuízo do consumidor. O que se invoca é a averiguação cautelosa da inversão do ônus da prova em favor de um consumidor, em dada situação concreta, e se isso não importará em sobrecarga incidente sobre o demandado, de modo a comprometer elementos salutares da atividade mercantil e função social da empresa.

Consideramos, por fim, que em alguns casos a vulnerabilidade possa se apresentar de forma bilateral/recíproca, e a benesse da inversão do ônus ou a negativa em deferi-la importará em prejuízo a qualquer das partes.

A esse respeito, defendemos que deva sobressair o interesse do consumidor, na medida em que o fornecedor tem como elemento intrínseco o risco da atividade e objetiva obtenção de lucro, merecendo, deste modo, suportar a máxima da teoria da reparação integral afeta à responsabilidade civil da atividade mercantil. Na disputa entre os igualmente frágeis, esses elementos deverão ser preponderantes a dar azo à melhor condição processual e material para o consumidor.

\section{CONSIDERAÇÕES FINAIS}

Desde a Constituição de 1891, a ordem econômica revelava o autoritarismo estatal marcante e, somente na Carta de 1934, sob influência dos movimentos do Estado Social coexistente a período de intenso crescimento industrial, foi que propostas governamentais de incentivo à economia encontraram espaço para eclosão.

Timidamente, a proteção do Estado às atividades empresariais se manifestava apenas pela coibição ao abuso do poder econômico cometido pela concorrência de mercado, o que era insuficiente, na medida em que as atividades decorrentes do emprego da mão de obra familiar necessitavam de mais do que igualdade formal.

$\mathrm{O}$ incentivo à proteção e fomento à microempresa e à empresa de pequeno 
porte contribui para o efetivo desenvolvimento da função social da empresa, do mesmo modo que colaborou para a reumanização da atividade institucional corporativa.

O abuso econômico, conforme mencionado, representava muito mais do que pretendiam os mandamentos constitucionais, revelando-se em outros vieses, como na falta de tratamento de igualdade material para os agentes econômicos em atividade de mercado.

Não apenas o abuso concorrencial prejudicava a saúde empresarial. Era preciso que fossem transpostos os entraves de sobrecarga tributária e outras ausências de tutela, que impunha que atividades mercantis fossem natimortas pelo não atendimento às necessidades específicas dos grupos empresariais, com caracteres que hoje os qualificam como microempresas e empresas de pequeno porte.

Essas atividades de mercado necessitam de tratamento favorecido e diferenciado, tal como a Constituição Federal de 1988 elencou como princípio norteador de política pública, ressaltando a necessidade de amparo normativo especial a fim de fomentar o crescimento empresarial e propiciar a circulação econômica e financeira.

Sublinha-se que isso justifica a revisão de regras e a criação de outras novas, focadas no engrandecimento e fortalecimento do desenvolvimento da nação de forma mais justa e equânime, em tributo ao consagrado princípio da livre iniciativa.

$\mathrm{O}$ reconhecimento da necessidade de tratamento isonômico às microempresas e empresas de pequeno porte pelo ordenamento pátrio reflete-se no aspecto material e processual, incluindo o âmbito da Justiça Laboral, que deve aplicar a norma, protegendo o vulnerável obreiro, sem prejuízo de assegurar o melhor interesse social, o equilíbrio e a crença na Justiça, genuinamente justa.

Tendo como norte a equidade, defendemos a possibilidade de relativização da inversão do ônus da prova, na seara de relação de consumo. É preciso sopesar, casuisticamente, as garantias processuais, afastando o formalismo e mecanicismo de decisões para, verdadeiramente, reconhecer proteção àquele que, de fato, encontrese mais frágil na relação jurídico-processual.

A possibilidade de inversão do ônus da prova é direito básico do consumidor, tal como do trabalhador, quando em litígio com fornecedores e empregadores, respectivamente. Processualmente, isso os isenta de provar afirmação 
feita, exigindo que o ex adverso prove não ter agido errônea ou ilicitamente. Tem-se por hipossuficiente não apenas quem se encontra em situação de insuficiência ou fragilidade econômica; merece ser reconhecido conceito mais ampliativo do termo, ou seja, que permita que seja verificada a situação de inferioridade ou desvantagem em geral, em cada caso.

Desta forma, propõe-se escrutinar o ônus da prova a partir dos fundamentos que o autorizam, objetivos e princípios basilares também para recepcioná-lo à ótica da micro e pequena empresa, na realização isonômica das demandas judiciais, resguardando a proteção estatal à livre iniciativa, valorização do trabalho humano e função social da empresa, ponderando interesses socioeconômicos e o objetivo das regras que reconhecem a hipossuficiência.

Por fim, apontamos que, embrionariamente, estamos imprimindo estudos $^{23}$ outros na busca pelo equilíbrio da prestação jurisdicional voltada para a tutela das microempresas e empresas de pequeno porte. Por ora, destaca-se a possibilidade de relativização da responsabilidade civil objetiva nas relações entre pessoas jurídicas, estampada pela leitura conjugada do parágrafo único do art. 927 e art. 931 do Código Civil. Registra-se ainda a emergente necessidade de revisitação das questões relativas ao procedimento de recuperação judicial, a fim de evitar a proteção deficiente (untermassverbot) do Estado.

Encerra-se este ensaio registrando que nossa proposta parte do entendimento de que, para ser eficiente, a livre iniciativa depende de instrumentos que permitam atividade empresarial econômica exitosa e próspera, em todas as especificidades, eis que resguardam interesse público e social, para além do interesse societário, individualmente considerado. Avante da seara geral, as microempresas e empresas de pequeno porte, idiossincrasias, necessitam de aparato jurídico especial para o desenvolvimento efetivamente livre e produção dos efeitos positivos almejados, cumprindo, assim, sua função social.

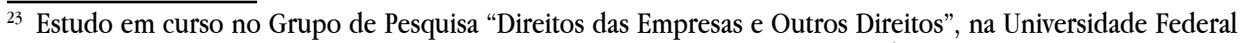
Fluminense, Departamento de Direito de Macaé, desde o semestre letivo 2014.2. 


\section{REFERÊNCIAS}

ALMEIDA, Amador Paes de (Coord.). Comentários ao Estatuto da Microempresa e Empresa de Pequeno Porte. São Paulo: Saraiva, 2009.

ASQUINI, Alberto. Profili dell' impresa. Rivista di diritto commerciale, Milano, v. XII, parte I, 1943.

BELTRÃO, Hélio. A Pequena e média empresa como fator de estabilidade política, econômica e social. Senai: Brasília, 1983.

BONAVIDES, Paulo; ANDRADE, Paes de. História Constitucional do Brasil. 3. ed. Rio de Janeiro: Paz e Terra, 1991.

BRASIL. Congresso Nacional. Lei $\mathbf{n}^{0} \mathbf{1 3 . 0 4 3}$, de 13 de novembro de 2014. Dispõe sobre os fundos de índice de renda fixa, sobre a responsabilidade tributária na integralização de cotas de fundos ou clubes de investimento por meio da entrega de ativos financeiros, sobre a tributação das operações de empréstimos de ativos financeiros e sobre a isenção de imposto sobre a renda na alienação de ações de empresas pequenas e médias; prorroga o prazo de que trata a Lei $\mathrm{n}^{0} 12.431$, de 24 de junho de 2011; altera as Leis $\mathrm{n}^{\mathrm{0}} 10.179$, de 06 de fevereiro de 2001, 12.431, de 24 de junho de 2011, 9.718, de 27 de novembro de 1998, 10.637, de 30 de dezembro de $2002,10.833$, de 29 de dezembro de 2003, 12.996, de 18 de junho de 2014, 11.941, de 27 de maio de 2009, 12.249, de 11 de junho de 2010, 10.522, de 19 de julho de 2002, 12.546, de 14 de dezembro de 2011, 11.774, de 17 de setembro de 2008, 12.350, de 20 de dezembro de 2010, 9.430, de 27 de dezembro de 1996, 11.977, de 07 de julho de 2009, 12.409, de 25 de maio de 2011, 5.895, de 19 de junho de 1973, 11.948, de 16 de junho de 2009, 12.380, de 10 de janeiro de 2011, 12.087, de 11 de novembro de 2009, 12.712, de 30 de agosto de 2012, 12.096, de 24 de novembro de $2009,11.079$, de 30 de dezembro de 2004, 11.488, de 15 de junho de 2007, 6.830, de 22 de setembro de 1980, 9.532, de 10 de dezembro de 1997, 11.196, de 21 de novembro de 2005, 10.147, de 21 de dezembro de 2000, 12.860, de 11 de setembro de 2013, 9.393, de 19 de dezembro de 1996, 9.250, de 26 de dezembro de 1995, 12.598, de 21 de março de 2012, 12.715, de 17 de setembro de 2012, 11.371, de 28 de novembro de 2006, 9.481, de 13 de agosto de 1997, 12.688, de 18 de julho de 2012, 12.101, de 27 de novembro de 2009, 11.438, de 29 de dezembro de 2006, 
11.478, de 29 de maio de 2007, 12.973, de 13 de maio de 2014, 11.033, de 21 de dezembro de 2004, 9.782, de 26 de janeiro de 1999, 11.972, de 06 de julho de 2009, 5.991, de 17 de dezembro de 1973, 10.406, de 10 de janeiro de 2002, 9.514, de 20 de novembro de 1997, 11.775, de 17 de setembro de 2008, 10.150, de 21 de dezembro de 2000, e 10.865, de 30 de abril de 2004, e o Decreto-Lei $n^{\circ} 911$, de $1^{\circ}$ de outubro de 1969; revoga dispositivos do Decreto-Lei $\mathrm{n}^{\mathrm{0}} 1.569$, de 08 de agosto de 1977, das Leis $\mathrm{n}^{0}$ 5.010, de 30 de maio de 1966, e 8.666, de 21 de junho de 1993, da Medida Provisória ${ }^{0}$ 2.158-35, de 24 de agosto de 2001, e do Decreto-Lei $\mathrm{n}^{\mathrm{o}} 1.598$, de 26 de dezembro de 1977; e dá outras providências.

BRASIL. Congresso Nacional. Lei $\mathbf{n}^{\mathbf{0}} \mathbf{1 2 . 1 5 3}$, de 22 de dezembro de 2009. Dispõe sobre os Juizados Especiais da Fazenda Pública no âmbito dos Estados, do Distrito Federal, dos Territórios e dos Municípios.

BRASIL. Congresso Nacional. Lei $\mathrm{n}^{\mathrm{o}} 10.406$, de 10 de janeiro de 2002. Institui o Código Civil.

BRASIL. Congresso Nacional. Lei $\mathbf{n}^{\mathbf{0}} \mathbf{1 0 . 2 5 9}$, de 12 de julho de 2001. Dispõe sobre a instituição dos Juizados Especiais Cíveis e Criminais no âmbito da Justiça Federal.

BRASIL. Congresso Nacional. Lei no $\mathbf{9 . 0 9 9}$, de 26 de setembro de 1995. Dispõe sobre os Juizados Especiais Cíveis e Criminais e dá outras providências.

BRASIL. Congresso Nacional. Lei no 8.078 , de 11 de setembro de 1990. Dispõe sobre a proteção do consumidor e dá outras providências.

BRASIL. Constituição da República Federativa do Brasil, de 05 de outubro de 1988.

BRASIL. Constituição da República Federativa do Brasil de 1967.

BRASIL. Constituição dos Estados Unidos do Brasil, de 1946.

BRASIL. Constituição dos Estados Unidos do Brasil, de 1937. 
BRASIL. Decreto no 22.626, de 07 de abril de 1933.

BRASIL. Decreto-Lei ${ }^{0} 5.452$, de $1^{\circ}$ de maio de 1943 . Aprova a Consolidação das Leis do Trabalho.

BRASIL. Lei Complementar $\mathrm{n}^{0}$ 123, de 14 de dezembro de 2006.

BRASIL. Lei Complementar no 147, de 07 de agosto de 2014.

BRASIL. Lei $\mathrm{n}^{0}$ 10.406, de 10 de janeiro de 2002.

BRUSCATO, Wilges. Manual de direito empresarial brasileiro. São Paulo: Saraiva, 2011.

D’ÁVILA, Luiz Felipe et al. As Constituições Brasileiras: Análise histórica e propostas de mudanças. São Paulo: Brasiliense, 1993.

DUARTE, Márcia Michele Garcia; PINHO, Humberto Dalla Bernardina de. Os Juizados Especiais Cíveis e o e-Process: o exame das garantias processuais na esfera virtual. Disponível em: < http://www.redp.com.br/arquivos/redp_3a_edicao. pdf>. Acesso em: jan. 2016.

DUARTE, Ronnie Preuss. Teoria da Empresa à luz do novo Código Civil Brasileiro. São Paulo: Método, 2004.

GONÇALVES, Sérgio de Castro. Patrimônio, família e empresa: um estudo sobre a transformação no mundo da economia. São Paulo: Negócio, 2000.

GRINOVER, Ada Pellegrini et al. Código Brasileiro de Defesa do Consumidor: comentado pelos Autores do Anteprojeto. v. I, rev. atual. e reformulada. 10. ed. Rio de Janeiro: Forense, 2011.

IBGE. Sala de Imprensa. Brasil tem mais de 10 milhóes de empresas na informalidade. Disponível em: <http:/saladeimprensa.ibge.gov.br/ noticias?view $=$ noticia\&id $=1 \&$ busca $=1 \&$ idnoticia $=366>$. Acesso em: set. 2014 .

MENDONÇA, Saulo Bichara. Função social da empresa. Análise pragmática. Revista de Estudos Jurídicos UNESP. Disponível em: < http://seer.franca.unesp.br/index. 
php/estudosjuridicosunesp/article/view/479> . Acesso em: out. 2014.

MENEZES, Paulo Braga de. As Constituições Outorgadas ao Império do Brasil e ao Reino de Portugal. Arquivo Nacional, 1974.

NEVES, José Roberto de Castro. Uma Leitura do Conceito de Equidade nas Relações de Consumo. In: ANDRADE, André Gustavo Corrêa de. (Org.) A Constitucionalização do Direito: A Constituição como locus da Hermenêutica Jurídica. Rio de Janeiro: Lumen Juris, 2003.

OLIVEIRA, Otávio J. Pequena empresa no Brasil: um estudo de suas características e perspectivas. Revista Integração, São Paulo, ano XII, n. 44, p. 8, jan./mar. 2006. Disponível em: <ftp://ftp.usjt.br/pub/revint/5_44.pdf>. Acesso em: set. 2015.

PEREZ, Viviane. Função social da empresa. Uma proposta de sistematização do conceito. In: ALVES, Alexandre Ferreira de Assumpção; GAMA, Guilherme Calmon Nogueira da. Temas de direito civil-empresarial. Rio de Janeiro: Renovar, 2008.

RIZZARDO, Arnaldo. Direito de Empresa. 5. ed. rev. atual. e ampl. Rio de Janeiro: Forense, 2014.

Recebido em: 11 de maio de 2016 Acesso em: 21 de dezembro de 2016 